\section{Fertile arguments in the desert}

\section{from Jonathan Silvertown}

ECologists have been arguing recently about whether interspecific competition is responsible for observed patterns of animal distribution and abundance ${ }^{1,2}$. Whereas interspecific competition once seemed to be the only process of interest to the theoretically minded, now dispersal, predation, mutualism and biogeographic history are also being considered (see ref. 1). Strangely, the recent debate has occurred almost exclusively among animal ecologists but similar arguments among plant ecologists now seem to be approaching the same conclusion.

Plant ecologists studying species distri-

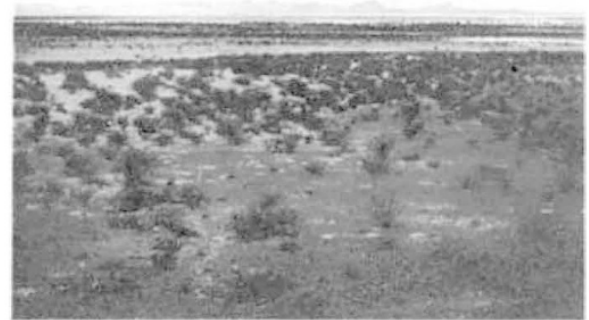

Larrea bushes in the Chihuaha desert.

bution in deserts have investigated the cause of the regular spatial patterns of distribution often found in the southwestern deserts of North America and elsewhere. The commonest shrub in the Chihuahua, Sonora and Mojave deserts is the creosote bush Larrea tridentata, which is a conspicuous part of the sparse vegetation. Bushes, or clumps of bushes, commonly have large areas of bare ground between them and often appear regularly spaced. F. W. Went suggested that this regular spacing is the result of allelopathic (toxic) interactions between bushes ${ }^{3}$. Since then, in one of the first quantitative analyses of the dispersion pattern of Larrea, S. R. J. Woodell et al. ${ }^{+}$showed that Larrea bushes are indeed regularly spaced at sites of low rainfall but are aggregated at sites of high rainfall. In an alternative hypothesis they suggested that the regularity is the result of competition for water between roots of adjacent bushes, with reduced competition at sites of high rainfall allowing aggregation.

M. G. Barbour ${ }^{5 / 6}$ found that regular patterns of Larrea were in fact quite rare. D. J. Anderson ${ }^{7}$ further questioned Woodell et al.'s claim that plants in lower rainfall areas compete for water, because bushes at these sites are at such low density that each plant actually has more available soil water than in high rainfall areas where bushes are more crowded. T. J. King and Woodell ${ }^{\circ}$ replied that the quantity of water available to bushes cannot be calculated simply from density and rainfall measurements because plant size. surface-water runoff and infiltration of water into the ground also has to be considered. They also suggested that periods of severe drought in the past might at some sites be responsible for present-day distributions. Thus, in defending the competition hypothesis, they acknowledge the importance of other factors in structuring Larrea communities, as animal ecologists have had to do in defence of similar arguments about interspecific patterns.

The parallel with the debate among animal ecologists can be taken further. Reassessment of competition in animal ecology has been stimulated by the use of 'null models' that predict how community structure would appear in the absence of competitive interactions between species. T. A. Ebert and G. S. McMaster ${ }^{10}$ have used this approach to challenge the regularity of spacing patterns in Larrea, which they believe may be no more than an artefact of sampling methods, by which plants that grow very near one another are recorded as a single individual. They show that this can cause a random pattern to appear erroneously as a regular one. King and Woodell" dispute this claim, but do not explain how the competition hypothesis accounts for regular spaced clumps.

A general conclusion from the use of null models in animal ecology has been that patterns can only provide correlative evidence of the processes that structure communities. Experiments are needed to test hypotheses generated by analysis of pattern distribution. Several relevant experiments have now been performed with desert shrubs. In the field, removing neighbours of individuals of both Larrea

Excitation-contraction coupling The messenger across the gap

\section{from Andrew P. Somlyo}

Excitation of the surface membrane of muscle results in release of calcium that is stored in an intracellular membrane system, the sarcoplasmic reticulum (SR); the $\mathrm{Ca}^{2+}$ released into the cytoplasm, acting through regulatory sites on Ca-binding proteins, initiates contraction. The signal from the membrane is communicated to the SR at specialized regions (triads, diads or surface couplings) where the cytoplasmic leaflets of the SR are connected to the surface membranes by quasi-periodic bridging structures across a $12-20 \mathrm{~nm}$ gap (refs 1,2; see figure). A major unresolved problem is the mechanism by which depolarization (or some other change in the surface membrane) is communicated and another desert shrub, Ambrosia dumosa, affects the physiological water status of other plants ${ }^{12:: 3}$. Even though this is evidence of competition for water, some of the experimental populations were aggregated. Clearly, competition does not lead inevitably to regular spacing.

We can say more than this. The desert perennial Eriogonum inflatum with competitors nearby is more likely to die than those plants with more distant neighbours, yet this does not change the degree of aggregation in the population. The most elaborate recent experiment "shows how uncertain the role of root competition in producing regular spacing has become. Despite a fall in shrub density, W. $\mathrm{H}$. Schlesinger and C. S. Jones found no change in the dispersion pattern of Larrea and Ambrosia at a Mojave site that has been deprived of surface water runoff by a drainage system for 45 years.

Ironically, the unknown causes of regular spacing in desert plant communities may bear some relationship to the way in which animal and plant ecologists have ignored each other. Few have considered, for example, that these plant patterns could result from the activities of seedgathering rodents ${ }^{16}$ which forage and remove seeds between bushes and which are ubiquitous in these deserts.

Strong. D. R. et al. Ecological Communities. Conceptuat Issues and the Evidence (Princeton Lniversity Press. 1984). Harvey. P. H. et al. A. Rev. Ecol. Sist. 14, 189 (1983).

Went. F. W. Scient. Am. 192, 68 (1955).

Woodell. S. R. J. et al. J. Ecol. 57, 37 (1969)

Barbour. M. G. Ecology 50, 678 (1969)

Barbour. M. G. Am. Midl. Nat 89, 41 (1973)

Anderson. D. J. J. Ecol. 59.555(1971)

King. T. J.\& Woodell. S. R. J.J. Ecoi. 61,761 (i973) Gilpin. M. E. \& Diamond. J. M. Oecologia 52, 75 (1982)

0. Ebert, T. A. \& McMaster. G. S. J. Ecol. 69, 559(1981).

1. King, T. J. \& Woodeli, S. R. J. J. Ecol. 72, 295 (1984)

2. Fonteyn. P. J.\& Mahall, B. E. J. Ecol, 69, 883(1981)

13. Ehleringer, J. R. Oecologia 63, 153(1984)

4. Wright. S. J. Oecologia 54, $266(1982)$.

5. Schlesinger, W. \& Jones, C. Bot. Gaz. 145, $116(1984)$ 16. Brown, J. H. et al. A Rev. Ecol. Syst. 10. 20! (1979).

Jonathan Silvertown is a Lecturer in the Biology Department, The Open University, Milton Keynes MK7 6AA, UK. 